\title{
Thermoplastic Materials in the Dental Practice: A Review.
}

\author{
Bozhana Chuchulska ${ }^{1}$, Stoyan Yankov ${ }^{2}$, Ilian Hristov ${ }^{3}$, Svetlin Aleksandrov $^{4}$ \\ ${ }^{1,2,3,4}$ Department of Prosthodontics, Faculty of Dental Medicine, Medical University, Plovdiv 4000, Bulgaria
}

\begin{abstract}
Thermoplastic materials (TMs) are composites (co-polymers) that possess the quality of flexibility. They were introduced in dentistry in the 1950s as an alternative to acrylics. TMs have the following characteristics: no residual monomer, no toxic or allergenic additives, high biocompatibility and the ability to keep their shape. At present, the following groups of TMs are used for the fabrication of flexible removable dentures: acetylates, polyamides, thermoplastic acrylic resins, polyolefins and polyesters. These are all nonmonomer, high-molecular compounds from different chemical elements with different properties. TMs are made of linear or less branched chains, they can soften during heating and solidify upon cooling.
\end{abstract}

Keywords: Thermoplastic materials, flexible dentures, polymers

\section{Introduction}

According to some prognosis, in the year 2025, it is predicted that half of the earth's population will be over the age of 50. Regardless of the dental prophylaxis, the majority of this population will require a full or partial removable dentures. For the purpose of improving the patient's quality of life, it is vital for them to be provided with aesthetic and fully functional dentures.

The acrylic resins are the most used denture base material at the moment. They have several advantages: a simple laboratory protocol, no special equipment is required, satisfactory aesthetics, satisfactory strength and a low price. Disadvantages are also considered: intake of fluids, porous structure, residual monomer, discolouration over time, insufficient mechanical strength, easy aging of the material.

Thermoplastic materials (TMs) are an alternative to acrylics. Nylon polyamides were first synthesized in 1950 as a member of the group of thermoplastic polymers. The first documented case of use of TMs as a denture base material belongs to Arpad and Tibor Nagy. In 1959 they started the Valplast company.

The first thermoplastic fluoropolymer suitable for flexible dentures was introduced in 1962 by the company Rapid Injection System. In the same year, thermoplastic acetate was suggested as a strong denture base material and in 1986 the company Dental D used it for aesthetic clasps, as they are flexible and need no periodical activation.

The TMs used in dentistry are composite materials (copolymers) that possess the quality of flexibility. These materials have the following characteristics: no residual monomer, no toxic or allergenic additives, high biocompatibility and the ability to keep their shape. The high flexibility and accuracy, as well as the variety of shades expand the use of TMs for full and partial dentures, immediate dentures, post resection dentures and temporary dentures after implantation.

At present, the following groups of TMs are used for the fabrication of flexible removable dentures:
- Polyamides

- Acetylates

- Thermoplastic acrylic resins (no residual monomer)

- Polyolefins

- Polyesters

These are all non-monomer, high-molecular compounds from different chemical elements with different properties. The name thermoplastic comes from the ability of the solid resin to transform into liquid when heated. TMs are made of linear or less branched chains, that means they can soften during heating and solidify upon cooling. The long molecule of TMs determines the quality of flexibility and high mechanical stability. The linear molecular type sets the high density of the material, but also a complicated laboratory protocol.

\section{Polyamides}

This is the most preferred choice of material within the group of TMs. They have been used since 1938 as toothbrush hairs, but obtained their name "Nylon" in New York in 1939. Polyamides are heterochain polymers with an amide group. These groups are polar and can form long hydrogen bonds with each other (fig. 1).

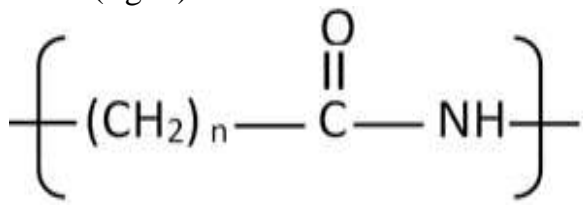

Figure 1: Chemical structure of a polyamide.

Polyamides are of two types:

1) Homopolymers obtained by the polycondensation of diamine and carbonic acid

2) Copolymers obtained by the copolymerisation of two or more molecules of diamine and carbonic acid.

There are polyamides $6,11,12^{*}$, where macromolecules contain only one type of monomer, whilst $66,69,610^{*}$ contain two different types of monomers

* The digits before the polyamide show the number of the carbon atoms included in the monomer.

\section{Volume 6 Issue 12, December 2017}




\section{International Journal of Science and Research (IJSR) \\ ISSN (Online): 2319-7064 \\ Index Copernicus Value (2016): 79.57 | Impact Factor (2015): 6.391}

The macromolecule in a solid state usually has a flat zigzag shape (fig. 2). Due to the amide group the polyamide macromolecules form carbon bonds between each-other, which determines the high melting temperature of the crystal polyamide.

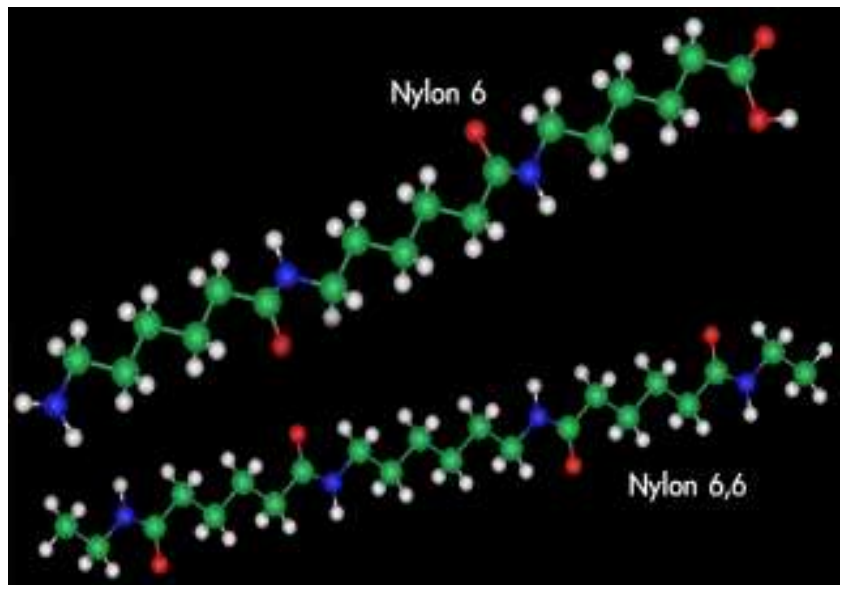

Figure 2: Nylon 6 and Nylon 66 molecular structure models

The polyamides can not be dissolved in solvents such as alcohol, acetone, ketone or other aromatic hydrocarbons and do not uptake liquids. They can withstand mechanical damage and high temperatures. The polyamides also possess sufficient hardness and resistance to hydrolyse at room temperature.

The polyamides used in dentistry are non-toxic and aliphatic. Their molecule has a flat chain configuration made of very long units, containing over 200,000 hydrocarbon atoms. Aliphatic polyamides possess high strength, wear resistance, resistance to decay and bacterial influence. They are used for fabrication of full and partial removable dentures.

Acetal-Polyoxymethylene.

The manufacturing of Polyoxymethylene began in US in 1960, but is used for dental purposes as a non brittle resin in year 1970 (fig. 3).

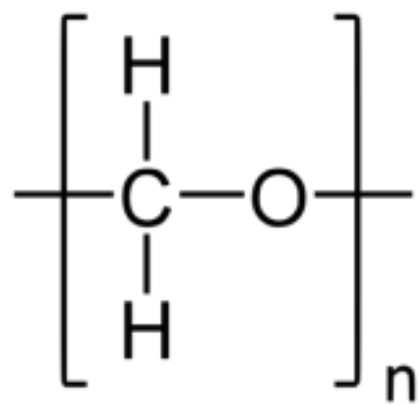

Figure 3: Polyoxymethylene - chemical formula

The polyoxymethylene has a long chain of alternating oxygen bonded methylene groups. It has a crystalline structure with no residual monomer. This polymer can be synthesized in two forms: homopolymer or heteropolymer. The latter possesses better mechanical properties and stability. In the solid state this compound has a white colour and molecular mass from 10,000 to 30,000 . Polyoxymethylene does not have high thermal and chemical stability, but it has high hardness and wear resistance, and also a high working temperature. It is a hydrophobic molecule, insoluble in chemical solvents and can be processed through high pressure casting. This is a non-toxic polymer with high dynamic hardness, stability and strength at $100^{\circ} \mathrm{C}$, high wear resistance to friction. Due to its dense structure and smooth surface, no plaque, stains or smell are retained. Over $90 \%$ of polyoxymethylene is used to replace coloured metals and alloys in different industries. The economical benefits come from the fact that the polymers do not require complicated processing unlike the metals.

The acrylic resins used in dentistry are non-modified to avoid toxic and allergenic reactions. Their mechanical stability is approximately 20 times lower than the stability of other dental materials suitable for dentures, whilst the stability of polyoxymethylene dentures is comparable with the stability of the removable cast metal dentures. Due to their high precision and minimal discrepancy polyoxymethylene polymers successfully replace metal alloys in fabrication of removable dentures with precision attachments.

Thermoplastic acrylic resins.

The main difference between the thermoplastic acrylic resins and the classical acrylic resins is the absence of residual monomer. Polymethylmethacrylate $\left(\mathrm{C}_{5} \mathrm{O}_{2} \mathrm{H}_{8}\right)_{\mathrm{n}}$ is an amorphous, transparent thermoplastic material, where the molecular mass can reach up to several millions. It is soluble in its own monomer and aromatic compounds such as ketones and formic acid. The material is non-toxic and it is stable in water, alcohol, simple aromatic hydrocarbons, saliva and stomach acids. It has high wear resistance, mechanical strength, aesthetics and variation of shades [Fig.4].

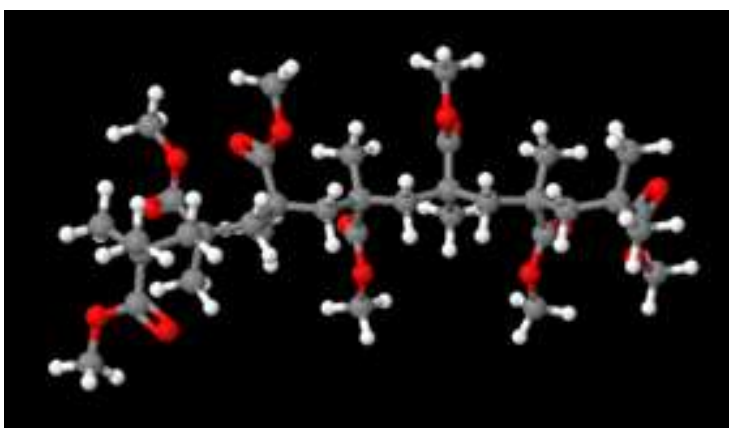

Figure 4: Ppoly(methyl methacrylate) molecular model.

Through heating over $120^{\circ} \mathrm{C}$, the polymethylmethacrylate starts melting and goes into high elastic state and can be easily moulded. After $200^{\circ}$ C starts evident depolymerisation, which accelerates above $300^{\circ} \mathrm{C}$. In dentistry, methylmethacrylate resin is used mainly for full and partial removable dentures.

\section{Polyolefins}

This group includes thermoplastic materials such as polybutene, polyethylene, polypropylene. These are flavorless, inodorous, amorphous, non-toxic polymers. Their mechanical stability depends on their molecular weight. Due to their good mechanical and aesthetic qualities they are popularly utilized in dentistry. The most used member of this group is polypropylene - a semi-crystalline transparent polymer with stable colour, that does not absorb liquid.

\section{Volume 6 Issue 12, December 2017}




\section{International Journal of Science and Research (IJSR) \\ ISSN (Online): 2319-7064}

Index Copernicus Value (2016): 79.57 | Impact Factor (2015): 6.391

Polypropylene has a molecular weight between 75,000 and 200,000 and has high wear resistance. It is indicated for partial removable dentures, temporary dentures and implant supported dentures.

\section{Polyesters}

A group of polymers containing ester functional group in their main chain. Polyesters include naturally occurring chemicals, such as in the cutin, as well as synthetics such as polycarbonate. They possess good mechanical properties high impact strength, high resistence to environmental impact, stability in temperature range from $-40^{\circ} \mathrm{C}$ up to $+120^{\circ} \mathrm{C}$. The polyesters are also elastic (elastic modulus $1490 \mathrm{MPa}$ ) and biocompatible. They are transparent and easy to polish. These qualities make Polyesters suitable for temporary fixed dentures and recently for removable dentures. The working temperature is between $230^{\circ} \mathrm{C}$ and $290^{\circ} \mathrm{C}$.

\section{References}

[1] E. Vares, Y. Vares, V. Nagurniy, "[The way of the thermoplastics in prosthetic dentistry]," Dentistry today, 2003(8):38. Russian.

[2] S. Ivanov, [Dental materials for dental technicians], Infodent BG, Sofia, 2016. Bulgarian.

[3] S. Ivanov, T. Drajev. [Flexible resins]. Sofia Medical University Press, Sofia, 2016. Bulgarian.

[4] Wadachi J, Sato M, Igarashi Y, "Evaluation of the rigidity of dentures made of injection-molded materials,"Dent Mater J 2013; 32: 508-511.

[5] A. Dezertinskiy, "[Thermoplastics. What do we know about them],’Dental Institute, 2007;2(35):98-101. Russian.

[6] V. Kuleznev, V. Shershnev, [Physics and chemistry of polymers], Kolos, Moscow, 2007. Russian.

[7] M. Negrutiu, C. Sinescu, M. Romanu, D. Pop, S. Lakatos. Thermoplastic resins for flexible framework removable partial dentures. TMJ. 2005 Sep;55(3):295-9.

[8] K. Singh, et all., "Flexible Thermoplastic Denture Base Materials for Aesthetical Removable Partial Denture Framework," Journal of Clinical and Diagnostic Research. 2013 Oct, Vol-7(10): 2372-2373.

[9] I. Averko-Antonovich, R. Bikmullin, [Methods for Investigating the Structure and Properties of Polymers], KGTU Press, Kazan, 2002. Russian.

[10] Ch. Bechev. [The physics of polymers]. Sofia UCTM Press, Sofia 2005. Bulgarian.

[11]RG. Craig, JM. Powers , JC. Wataha, Dental materials, properties and manipulation. 8th Ed., St. Louis, Mosby Inc., 2004:121.

[12] T. Savitskaya, [Structure and properties of polymers. Chemistry: report of problems], Belarusian State University Press, Minsk, 2000. Russian.

[13] A. Battistelli, "Der Einatz von Thermoplastischen AzetalkunststofTen in der Kronen- und Bruckentechnik," Quintessence of Technology 16(3): 511, (1991). 129.

[14]RG. Craig , JM. Powers, RL. Sakaguchi. Craig's restorative dental materials. 13th ed. St. Louis: Mosby Elsevier, 2011:51-52.
[15]E. Nesterko, M. Butova.[The Use of Polymeric Materials in Modern Dentistry]. Young Scientist. 2015(24-1):49-51. Russian.

[16]I. Tregunov, R. Boldyreva, L. Mihaylenko, V. Maglakelidze, S. Tregubov, The Use of Thermoplastic Materials in Dentistry, Medical Press, Moscow, 2007.

[17] P. Velev, [Processing of plastics], Sofia UCTM Press, Sofia, 2005. Bulgarian

[18] M. Ogorodnikov, "Improving the properties of basic materials used in orthopedic dentistry: stages of development, improvement and perspective directions," Dentistry, 2004;8(6):69-74.

[19] Stafford GD, R. Huggett, AR. MacGregor, J. Graham, "The use of nylon as a denture-base material," J Dent 1986; 14: 18-22.

[20] A. Battistelli. Nuove soluzioni per protesi provvisori con lega acetalica per fusione. Quintessenza Odontotecnica 12: $1113-1128,1989$.

[21]A. Battistelli. Nouvelles solutions pour prothèses prowisoires en resine acetaligue thermoplastigue par fusion et injection. Art \& Technigue Dentaires ATD 2: 103109, 1991.

[22] K. Fueki, M. Yatabe, Ch. Ohkubo, et all., "Clinical application of removable partial dentures using thermoplastic resin - Part II: Material properties and clinical features of non-metal claps dentures," J of Prosthodontic Research 58.2014.71.84.

[23] K. Fueki, M. Yatabe, Ch. Ohkubo, et all., "Clinical application of removable partial dentures using thermoplastic resin - Part I: Definition and indication of non-metal claps dentures," J of Prosthodontic Research 58.2014.3.10.

[24] A. Puigpelat, J. Samson, J.M. Anglada, E. Ortiz, "Nuevo material eátetico en protesis partial removable," Polioximetileno o resina acetálica. Odonto Estomatología 2: 59-63, 1993.

[25] M. Simov, [Technologies and materials in modern Prosthodontics,] Varna Medical University Press, Varna, 2016.

[26]RG. Craig, "Denture materials and acrylic base materials," Curr Opin Dent. 1991 Apr;1(2):235-43.

\section{Author Profile}

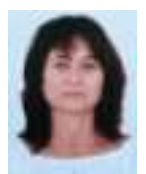

Bozhana Chuchulska received her MSc Degree from Medical University - Plovdiv, Faculty of Dental Medicine in 1993. She worked for 2 years as a General dentist. From 1995 she is an assistantprofessor at the Department of Prosthodontics in Medical University - Plovdiv, Faculty of Dental Medicine. She obtained a speciality in Prosthetic Dentistry in year 1998 and a speciality in General Dentistry in year 2005. Her Professional interests are in aesthetic removable dentures and flexible dentures. Faculty of Dental Medicine, Medical University, Plovdiv, Bulgaria. 3 Hristo Botev blvd., Plovdiv, Bulgaria

E-mail: bogana_68@abv.bg 